\title{
FORECASTING OF DEMAND QUANTITY OF CRYSTAL SUGAR IN INDONESIA
}

\author{
Muhaimin Abdul Wahib*, Sa'diyah Chalimatus, Hardana Andrean Eka \\ Faculty of Agriculture, University of Brawijaya, Malang, Indonesia \\ *E-mail: awmuhaimin@gmail.com
}

\begin{abstract}
Domestic sugar production increasingly unable to meet the needs of the community so that the shortage must be covered with imported sugar has continued to increase since 1990. Period 1991-2001, the sugar industry in Indonesia began to face a variety of significant problems. One indicator of Indonesia's sugar industry problem is the increasing trend of imports. The purpose of this research is to analyze the factors that influence the import of sugar crystal in Indonesia and to analyze the forcasting about Indonesian sugar import in the future. The projected amount of sugar imports in Indonesia in the coming years will continue to increase the import of crystal sugar in the next seven years by Indonesia reaching 425 thousand tons.
\end{abstract}

\section{KEY WORDS}

World sugar price, exchange rate, crystal sugar, demand.

Sugar is one of the commodities that play an important role in the agricultural sector, especially the plantation sub-sector in Indonesia. Sugar is also one of the basic needs of society and a relatively cheap source of calories (Agriculture Research and Development Berau, 2005). The position of sugar as a main sweetener can not be replaced by other materials used by both household and food and beverage industries.

Many factors affect the condition of the decline of sugar industry in Indonesia. In addition to reducing efficiency at the farm and sugar factory level, various factors such as government policy also significantly influence the decline of the sugar industry in Indonesia (Susila, 2005). The existence of sugar import policy raises the government's concern about high sugar imports, which is seen as a threat to food self-sufficiency. Food independence is important for a large populated developing country with relatively low purchasing power such as Indonesia. The stability of sugar prices in the domestic market at a level that can benefit the producers (sugar industry) and feasible for consumers, is an important thing to ensure the viability of the sugar industry and encourage the increase of national sugar production. Sugar needs can be fulfilled as one of the basic ingredients of society (Churrmen, 2001).

Domestic sugar production increasingly unable to meet the needs of the community so that the shortage must be covered imported sugar continues to increase from year to year since 1990. Period of 1991-2001, the Indonesian sugar industry is the tendency of increasing import volume. Limiting sugar imports needs to be done to maintain the continuity of the sugar industry while maintaining affordable property by the community.

Many factors are causing the increasing import of sugar, especially the inability of the domestic sugar industry to meet the increasing demand of the community's sugar due to the increase of population and the increasing of income per capita. Efforts to achieve selfsufficiency in sugar have been carried out by governments through various policies. The objectives of this research are (1) to analyze the factors influencing the demand of import sugar in Indonesia, (2) to analyze the forcasting of import sugar in Indonesia in the future. So it is expected to know the factors that affect the demand for sugar in Indonesia and the forecasting of Indonesian commodity sugar in the future and the government can be more appropriate in making policy. 


\section{METHODS OF RESEARCH}

The type and source of this research data is secondary data obtained from related institutions. Secondary data is data obtained from literature review and related institutions of research. Secondary data required are previous research results relevant to complement this research. The data were obtained by documentation and information retrieval from several related agencies, such as agriculture service, Central Bureau of Statistics (BPS), Indonesian Sugar Council, site of directorate general of plantation, (Ditjetben) and FAO website, USDA site, Word Bank website as well as various literature that support the preparation of this research. The type of data used is time series data from 1985-2013.

Quantitative analysis in this research use regression method with crystal sugar import equation model. After analyzing the equation model that will be used it will be followed by forecasting analysis. Forecasting method used in this study is a quantitative method that uses the method of forecasting regression model. This study uses a simple regression model to present the import activity of Crystal Crystals as its indendent variable, while other variables such as world sugar price, exchange rate, total demand of sugar crystal and the amount of imports of previous year become independent variable. The equation of simple regression model can be written as follows:

$$
M g=\alpha+\alpha_{1} P w+\alpha_{2} E R+\alpha_{3} Q d+\alpha_{4} M g t_{-1}
$$

Forecasting method done using regression model in this research with the help of SAS 9.1.3 analysis tool. Forecasting method using regression model has several stages of analysis that must be done, according to (Sinaga and Sitepu, 2006) following the steps that must be done starting from: Model Specifications; Model Estimation; Model Simulation; Forcast of the explanatory values of variables; Forcast of dependent value 5 or endogenous.

\section{RESULTS AND DISCUSSION}

Stage analysis forecasting use the regression model of spesification model, estimation model, simulation model, forecasting values explanatory variable and predict value dependent or endogenous. Forecasting directly be carried out from bentik who has appropriate (Sinaga and Sitepu, 2006). The one conducted prior to stage specification model is to identify to menetukan do data series used have stationary, namely if the data time series look fickle it around on a level that remains. Data time series not stationary so will look increasing or decreasing respect to time if the data series nonstasionermaka can be converted or become stationary with make fine distinctions, Namely data series native replaced in series of distinction.

The series data is made differentiation because the data initially indicates a stationary condition. Absolute stationary conditions are met for predictable forecasting. Results of stationary related variables studied ie imports. In the stationary test used is known from no 3 observations that exceed the standard limits of errors specified or 5 percent of the overall observations made.

The next stage is a model specification. Model specifications are the determining stages of the model used. In a study aimed at forecasting the importation of crystal sugar in Indonesia for the next seven years, the equation with simple regression model of sugar crystal import was prepared. The economic equation can be written Mg $=f(P w, E R, Q d$, Mgt1 ), whereas in the stochastic model can be written as follows:

$$
M g=\alpha+\alpha_{1} P w+\alpha_{2} E R+\alpha_{3} Q d+\alpha_{4} M g t_{-1}
$$

Where: $\mathrm{Mg}$ = Sugar crystal imported; $\mathrm{Pw}=$ world sugar price; $\mathrm{Er}=$ exchange rate; $\mathrm{Qd}=$ Crystals sugar demand of the previous year.

The next step is an estimation of the model performed with the help of SAS 9.1.3 software analysis tool by performing simple OLS regression analysis. After the estimation of 
the model is known the estimation and statistical test of the model used. Estimated model estimation results as follows:

$$
M g=-18.6771+1.392984 P w-8.63625 E R+3.180902 Q d+0.125407 M g t_{-1}
$$

Other estimation result is statistical test which consist of value of $R^{2}, F$ test, and test. The value of $R^{2}$ from the above equation model is 0,66170 , it shows that the sugar crystal equation, the imported sugar of the previous year was $66.17 \%$. Based on the results of testing the import model of Crystals conducted, it can be seen that the model used has been adequate. It is known from the probability value $F$ arithmetic an $F$ table so this indicates reject $\mathrm{H} 0$. Based on these results it can be concluded that all exogenous variables simultaneously affect the equation of sugar crystal imports. The value of t test shows all variables below 0.05 indicating that the variables in the equation significantly affect the import of sugar crystals.

The step of regression forecasting is model simulation; this is to test the accuracy of the model. Validation of this model aims to know the model used is good and appropriate to do the simulation or meramlkan value of the dependent variable. This stage will generate the criteria of model accuracy values. The values to be considered at this stage are mean error, mean\% error, theil forecast error statistic, RMS\% error, dist component and covar. The mean error value is -, 000003, this value indicates the bias is entirely decreased in the simulation value, in other words the average actual value underestimate the import model of crystal sugar by 0.0003 tons. The mean $\%$ error for this equation is 0,5151 , this value shows the average error rate to the crystal sugar import equation, in other words the average actual overestimate value is $0,5152 \%$.

The theile forecast error statistic value seen from the value of $U I$ and $U$, on this equation is 0,0627 and 0,0314 . This statistic is close to the ideal value of zero, indicating that the model simulation follows the actual data well. The value of RMS\% error of $7,3976 \%$, this value indicates that the equation model of crystal sugar import overestimate, in other words equation model follow the actual data with error rate of $7.39 \%$. Other values to be considered are the dist values and covars, the magnitude of dist and covar values of 1.00 and 0.90 . The ideal disk and covar value is close to 1 . Based on the available values it can be concluded that the parameter bias can be said to be not a serious problem and overall the model can be said to be good so the equation can be used as a forecast.

The next forecasting stage is independent and dependent varabel forecasting, this forecast is for the next 7 years from 2014 to 2020. The following forecasting results will be explained in the table below.

Table 1 - The results of forecasting logs of regression models

\begin{tabular}{|c|c|c|c|c|c|}
\hline Observation & Mg & Pw & ER & Qd & Mgp_1 \\
\hline 2014 & 5,63049 & 3,31928 & 0,17105 & 6,45204 & 5,32255 \\
\hline 2015 & 5,60800 & 3,31336 & 0,17666 & 6,46144 & 5,47231 \\
\hline 2016 & 5,60291 & 3,32610 & 0,18121 & 6,46847 & 5,56983 \\
\hline 2017 & 5,60558 & 3,34562 & 0,18498 & 6,47397 & 5,63591 \\
\hline 2018 & 5,61171 & 3,36519 & 0,18818 & 6,47846 & 5,68306 \\
\hline 2019 & 5,61937 & 3,38224 & 0,19097 & 6,48231 & 5,71882 \\
\hline 2020 & 5,62772 & 3,39666 & 0,19344 & 6,48574 & 5,74773 \\
\hline
\end{tabular}

The estimate forecasting result of the above regression model is still in log form, so it must be returned or diantilogkan to know the actual number. Here the result of forecasting regression model stelah diantilogkan so that shows the value of numbers in the initial or real form in the table 2.

Based on the result of forecasting analysis of regression model above can be knowed value of import crystal sugar in Indonesia in the future continue to increase although not in amount too big. This is because the sugar is a sugar sugar consumed by the community. In the sugar demand variable which is certainly influenced by the population and income does not necessarily change the amount of sugar demanded by the community. Increased imports 
of sugar crystals that are not too much may be due to decreased consumption or decreased individually these days.

Table 2 - Estimated Forecasting Results Antilog Regression Model

\begin{tabular}{|c|c|c|c|c|c|}
\hline Observation & Mg & Pw & ER & Qd & Mgp_1 \\
\hline 2014 & $427.061,09$ & $2.085,84$ & 1,48 & $2.831 .652,79$ & $201.159,97$ \\
\hline 2015 & $405.508,54$ & $2.057,60$ & 1,50 & $2.893 .610,02$ & $296.694,84$ \\
\hline 2016 & $400.783,65$ & $2.118,85$ & 1,52 & $2.940 .830,54$ & $371.389,82$ \\
\hline 2017 & $403.255,22$ & $2.216,26$ & 1,53 & $2.978 .310,69$ & $432.424,21$ \\
\hline 2018 & $408.987,47$ & $2.318,41$ & 1,54 & $3.009 .261,99$ & $482.014,39$ \\
\hline 2019 & $416.265,10$ & $2.411,24$ & 1,55 & $3.036 .057,55$ & 523.383 .47 \\
\hline 2020 & $424.345,89$ & $2.492,64$ & 1,56 & $3.060 .130,87$ & $559.409,71$ \\
\hline
\end{tabular}

It can be seen from the data collected by the national socio-economic survey institute shows that the decreasing condition in 2009 to 2013 are $79,4 \mathrm{Kg}, 76,9 \mathrm{Kg}$, and 73,8 $\mathrm{Kg}, 64,7$ $\mathrm{Kg}, 66,4 \mathrm{Kg}$ respectively overall consumption of sugar crystals decreased by $4,08 \%$. Increased demand for sugar is due to an increase in population. Imports of other sugars that show a very large increase in amounts are refined sugar. This is because the number of food and beverage industry in Indonesia continues to increase.

\section{CONCLUSION}

Factors affecting demand for import crystal sugar in Indonesia are world sugar price, exchange rate, and crystal sugar demand of previous year

The value of imports crystal sugar in Indonesia in the future continues to increase although not in an amount too large. This is because crystals sugar are the sugar consumed by the community. Increased demand for sugar is due to an increase in population. Imports of other sugars that show a very large increase in amounts are refined sugar. This is because the number of food and beverage industry in Indonesia continues to increase.

\section{REFERENCES}

1. Agriculture Research and Development Berau. (2005). Sugar Cane in Indonesia. Agriculture Berau. Jakarta.

2. Bernatonyte, D. Burksaitiene, D. \& Rimiene, K. (2013). Trade Specialization Pattern of Lithuania. Economics and Management: 2013. 18 (4).

3. Bernatonyte, D. \& Normantiene, A. (2009). Estimation of Trade Specialization: the Case of the Baltic States. Ekonomika-Engineering Economics (2).

4. Burger, K. Kameo, D. \& Sandee, H. (2001). Clustering of Small Agro-Processing Firms in Indonesia. International Food and Agribusiness Management Review, 2(3/4): 289-299.

5. Caporale, G. M. \& Sova, R. (2015). Trade Flows and Trade Specialisation: The Case of China. Working Paper No. 15-07.

6. Churmen, Imam. (2001). Save sugar industry in Indonesia. Millenium Publisher. Jakarta.

7. Dachliani, D. (2006). Demand of sugar import on 1980-2003 in Indonesia. (Thesis). Faculty of Economic. Diponegoro University. Semarang.

8. Delroy Anthony Armstrong.(2004). The Potential Impact of Trade Policychanges on Caribbean Sugar. B.S., Louisiana State University.

9. Dipl.-Ing. Dieter Bahndorf, Udo Kienle. (2004). World Market of Sugar and Sweeteners. OECD-FAO Agricultural Outlook 2016-2025, OECD Publishing, Paris.

10. Firmansyah, (2008). The Position of Competitiveness and Specialization Trading of Tea Indonesia in Facing Globalization.Brawijaya. University. Malang.

11. Gaynor, P.E., and R.C. Kirk Patrick.(1994). Tome Series Modeling and Forecasting in Business and Economics. New York, Mc Graw hill.

12. Haley, Stephen.2013. World Raw Sugar Prices The Influence of Brazilian Costs of Production and World Surplus/ Deficit Measures. United States Department of Agriculture 
13. Matsumura, Kanichiro.(2010). Demand and Supply Structure for Food in Asia. Sustainability 2011, 3, 363-395; doi: 10.3390/su3020363.

14. McConnell, Michael; Erik Dohlman; Stephen Haley. (2010). World Sugar Price Volatility Intensified by Market and Policy Factors.

15. McCormick, A. J. Watt, D. A. and Cramer, M. D.(2009). Supply and demand: sink regulation of sugar accumulation in sugarcane. Journal of Experimental Botany, Vol. 60, No. 2, pp. 357-364.

16. Rumánková, Lenka and Smutka, Luboš. (2013). Global Sugar Market - The Analysis Of Factors Influencing Supply and Demand. Volume LXI. No. 2, pp. 463-471.

17. Sa'diyah, C. (2014). Factors that influence of economic performance for crystal sugar in Indonesia. (Thesis). Faculty of Agriculture. University of Brawijaya. Malang.

18. Sinaga, N. (2006). Model Econometric Aplication. IPB Post Graduate. Bogor.

19. Susila, Wayan.R dan Bonar M. Sinaga. (2005). Analysis of Sugar Industry Policy in Indonesia. Jurnal Agro - Ekonomi Volume 23 No. 1, page 30-53

20. Xue Xu and Hailong Xia.(2014). Analysis and Outlook of China's Sugar Industry Development. Proceedings of Selected Articles of 2013 World Agricultural Outlook. 